OPEN ACCESS

Edited by:

Jean Paul Deslypere, Aesculape CRO, Belgium

Reviewed by: $\mathrm{Rao} \mathrm{Fu}$,

Sichuan University, China

Xiaonan Yang,

Guangxi Medicinal Botanical Garden,

China

${ }^{*}$ Correspondence: Te L

at1029@163.com

Specialty section: This article was submitted to

Drugs Outcomes Research and Policies,

a section of the journal

Frontiers in Pharmacology

Received: 29 January 2021 Accepted: 21 April 2021

Published: 29 April 2021

Citation:

LiX and LiT (2021) Inadequate Dosage May Lead to the Recurrence of Postoperative Pulmonary Hypertension in Patients With Congenital Heart Disease. Front. Pharmacol. 12:660405. doi: 10.3389/fphar.2021.660405

\section{Inadequate Dosage May Lead to the Recurrence of Postoperative Pulmonary Hypertension in Patients With Congenital Heart Disease}

\author{
Xinmei $L i^{1,2}$ and $T e L i^{2 *}$ \\ ${ }^{1}$ Yunnan Provincial Key Laboratory of Pharmacology, Kunming Medical University, Kunming, China, ${ }^{2}$ Department of Pharmacy, \\ Fuwai Yunnan Cardiovascular Hospital, Kunming, China
}

Background: Pulmonary arterial hypertension (PAH) associated with congenital heart disease (PAH-CHD) occurs predominantly among patients with uncorrected congenital heart disease (CHD). It is an intractable problem to control PAH continuously and stably after an operation.

Methods: 1) OPLS-DA combined with S-plot was used to retrospectively analyze the results of preoperative and postoperative $\mathrm{PAH}$ and 39 biochemical indicators of 235 patients admitted to Fuwai Yunnan Cardiovascular Hospital from January 2019 to December 2020. 2) Combined with Meta-analysis, the recurrence in postoperative PAH was analyzed in terms of operation factors, doses administered, and age factors.

Results: 1) 4 indicators (PAH, $\mathrm{RBC}, \mathrm{HGB}$, and $\mathrm{CO}_{2}$ ) that reflect the prognosis of patients had been found by OPLS-DA combined with S-plot. 2) The recurrence rate of postoperative PAH was $37.02 \%$. The comprehensive therapeutic effect of interventional closure was better than that of surgical operation. PAH was not significantly higher again in patients who received either the instruction dose or the literature dose. Postoperative combination therapy (bosentan and sildenafil) was more effective than bosentan alone. Recovery after treatment was better in infants than in the other four age groups.

Conclusion: OPLS-DA combined with S-plot was used for the first time to analyze clinical examination data. In this study, this method proved to be a feasible method for analyzing clinical data We recommend interventional closure as the first choice for patients with $\mathrm{PAH}$ $\mathrm{CHD}$. For postoperative oral therapy, we recommend the combination therapy (bosentan with sildenafil). To prevent the recurrence, the dose should be strictly prescribed according to the instructions, literature, or body surface area converted. Moreover, we recommend treatment at a young age in these patients.

Keywords: pulmonary artery hypertension, interventional closure, surgery, doses administered, sildenafil 


\section{INTRODUCTION}

Pulmonary arterial hypertension (PAH) associated with congenital heart disease (PAH-CHD) occurs predominantly among patients with uncorrected congenital heart disease (CHD). These patients have small cardiac defects (usually ventricular septal defects $<1 \mathrm{~cm}$ and atrial septal defects $<2 \mathrm{~cm}$ ) (Nazzareno et al., 2016). A significant number of patients have persistent or recurrent $\mathrm{PAH}$ after congenital heart repair surgery or percutaneous closure (Xi et al., 2019). Some studies speculate that this phenomenon may be due to high surgical risk (Mclaughlin et al., 2009; Kiefer and Bashore, 2011; Melby et al., 2011). However, no studies had shown the cause of recurrence and no detailed analysis of the indicators that lead to $\mathrm{PAH}$ recurrence.

The orthogonal projections to latent structures discriminant analysis (OPLS-DA) is an extension of the principal component analysis (PCA) and currently used mainly for metabolomics data analysis (Zhao et al., 2017). In contrast to basal metabolomics studies, data collection in the clinic is limited, and patient data are only collected at the time of initial consultation and routine examinations. Doctors are accustomed to ignoring normal values in these examinations and interpret abnormal values based on anecdotal rather than scientific evidence. Studies had shown that PCA can save doctors' time in analyzing clinical indicators ( $\mathrm{Li}$ and Li, 2020). In this study, OPLS-DA was used for the first time to analyze the routine clinical examination to identify reliable indicators related to the prognosis of patients with PAH-CHD.

Currently, randomized controlled trials of bosentan and sildenafil have been conducted in children (More et al., 2016; Kelly et al., 2017). However, most studies have mostly reported short-term preoperative use of a single drug (bosentan or sildenafil), with no reports of long-term ( $>9$ months) postoperative use (Gilbert et al., 2005; Ashraf and Midany, 2013). In the present long-term follow-up study, we retrospectively analyzed data from patients with $\mathrm{PAH}-\mathrm{CHD}$ who underwent correction (interventional closure or surgery).

\section{MATERIALS AND METHODS}

\section{Patients' Characteristics}

The institutional review board approved this study and waived the requirement for individual consent because of its retrospective nature. From January 1, 2019 solstice to December 31, 2020, 235 patients with PAH-CHD were admitted and treated in Fuwai Yunnan Cardiovascular Hospital, Kunming, China. We collected the data (PAH, postoperative medications, and 39 other indications from routine examinations) on these patients who underwent correction. Clinical and baseline characteristics of the data were preliminarily analyzed.

\section{Orthogonal Projections to Latent Structures Discriminant Analysis and S-Plot}

OPLS-DA of SIMCA 14.1 (Umetrics, Kinnelon, New Jersey) was utilized to analyze and compare the indicators of the preoperative and follow-up groups, and S-plot was made. Forty indicators were including $\mathrm{PAH}$ by echocardiography and routine examinations (liver function examination item, kidney function examination item, blood lipid examination item, blood electrolyte, blood cell

TABLE 1 | Inclusion and exclusion criterion for three times literature retrievals in Chinese and English.

\begin{tabular}{|c|c|c|c|}
\hline $\begin{array}{l}\text { Criterion } \\
\text { number }\end{array}$ & Keywords & Inclusion & Exclusion \\
\hline 1 & $\begin{array}{l}\mathrm{PAH}-\mathrm{CHD} \text {, interventional closure or surgery, } \\
\text { follow up }\end{array}$ & $\begin{array}{l}\text { Postoperative pulmonary arterial systolic blood } \\
\text { pressure was followed up }\end{array}$ & $\begin{array}{l}\text { 1) The study had no record of PAH; 2) Study combined } \\
\text { with multiple drug therapy }\end{array}$ \\
\hline 2 & $\mathrm{PAH}-\mathrm{CHD}$, sildenafil or bosentan & $\begin{array}{l}\text { 1) The dosage was clear; 2)The patient's weight } \\
\text { and age were clear }\end{array}$ & $\begin{array}{l}\text { 1) The study had no record of PAH; 2) Study combined } \\
\text { with multiple drug therapy }\end{array}$ \\
\hline 3 & $\begin{array}{l}\mathrm{PAH}-\mathrm{CHD} \text {, interventional closure or surgery, } \\
\text { sildenafil or bosentan }\end{array}$ & The patient was given medication postoperatively & $\begin{array}{l}\text { Patients were given medication during perioperative } \\
\text { period }\end{array}$ \\
\hline
\end{tabular}

TABLE 2 | Clinical and baseline characteristics of 235 patients.

\begin{tabular}{|c|c|c|}
\hline Characteristic & Minor group $(n=161)$ & Adult group $(n=74)$ \\
\hline Gender, male/female & $69 / 92$ & $29 / 45$ \\
\hline Weight, kg & $(19.83 \pm 18.96)$ & $(54.16 \pm 12.79)$ \\
\hline Age, year & $(6.42 \pm 5.38)$ & $(41.81 \pm 14.23)$ \\
\hline Right atrial pressure, $\mathrm{mm} \mathrm{Hg}$ & $(63.42 \pm 26.81)$ & $(68.51 \pm 14.53)$ \\
\hline Pulmonary vascular resistance, wood & $(18.41 \pm 13.73)$ & $(18.32 \pm 27.58)$ \\
\hline Pulmonary arterial systolic pressure, $\mathrm{mm} \mathrm{Hg}$ & $(73.74 \pm 20.87)$ & $(78.11 \pm 26.56)$ \\
\hline Mean pulmonary arterial, $\mathrm{mm} \mathrm{Hg}$ & $(55.46 \pm 15.57)$ & $(48.67 \pm 22.23)$ \\
\hline Interventional closure/surgery & $43 / 118$ & $20 / 54$ \\
\hline $\mathrm{PAH}$ recurrence, \% & $29.19 \%$ & $54.05 \%$ \\
\hline
\end{tabular}



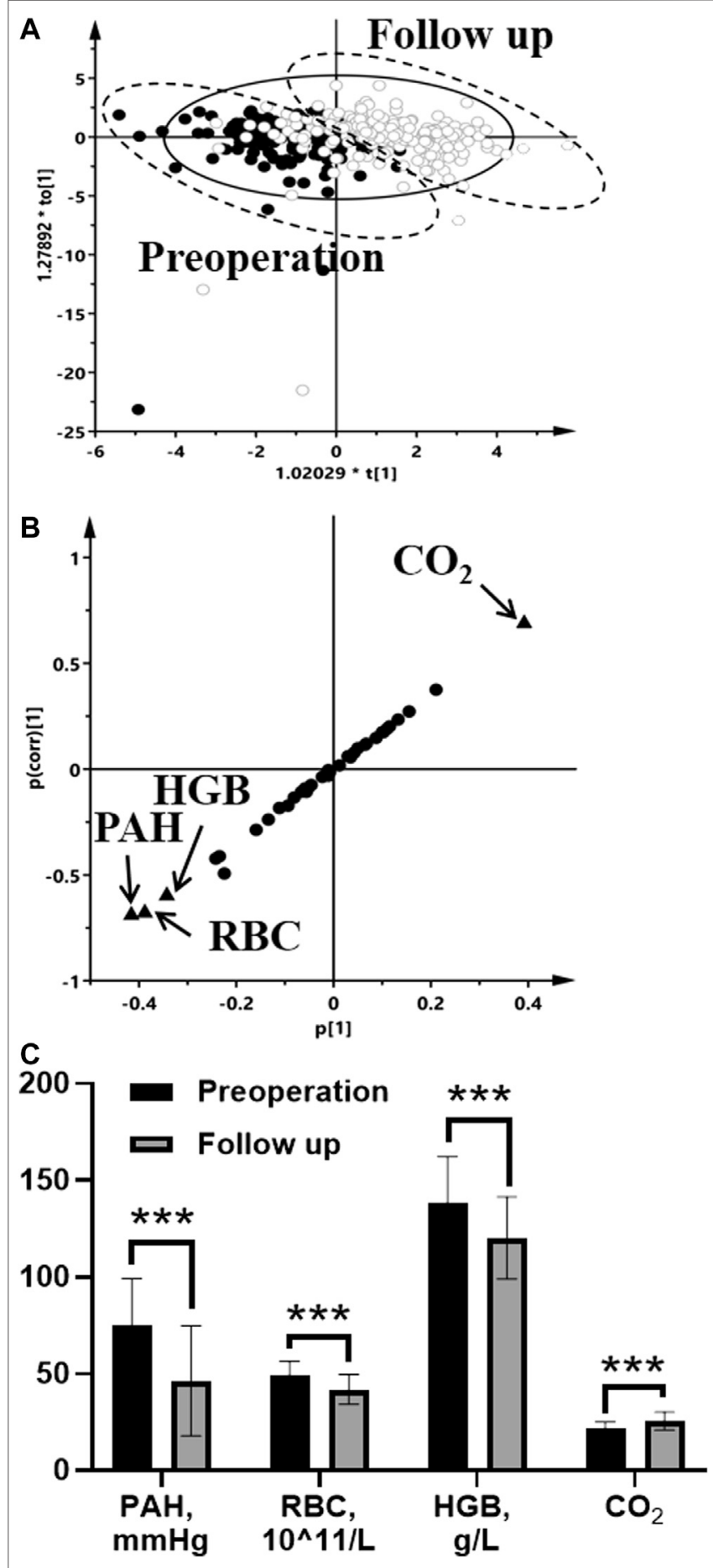

FIGURE 1 | Indicators analysis in the preoperative group and the follow-up group by OPLS-DA score plots (A), S-plot (B), and comparison of four difference indicators (C) ( $\bullet$, the preoperative group in score plots; $\bigcirc$, the follow-up group in score plots; four differential indicators are labeled in S-plots). Statistical analysis was performed using $t$ test. ${ }^{*} p<0.05 ;{ }^{* *} p<0.01 ;{ }^{* \star} p<0.001$.

examination item). Then, we identified the indicators in S-plot where the difference was more than 0.5 and less than -0.5 . The pre- and post-operative values of these different indicators were

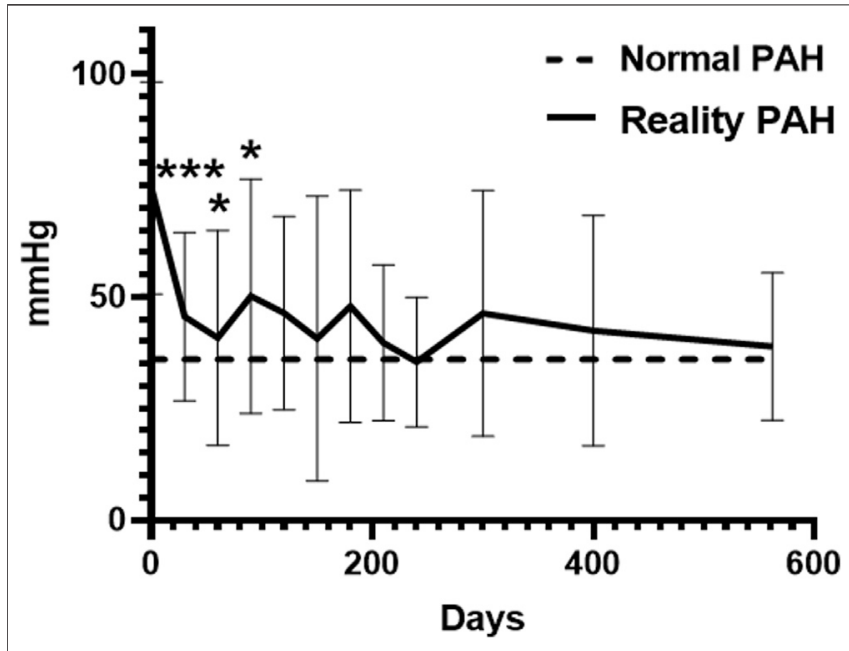

FIGURE 2 | PAH changes in 2 years including preoperation, postoperation, and follow up. ${ }^{*} p<0.05 ;{ }^{* \star} p<0.01 ;{ }^{\star \star \star} p<0.001$.

compared. The PAH indicators of the patients were analyzed over 2 years, including the preoperative group, the postoperative group, and the follow-up group.

\section{Analysis of the Causes of Pulmonary Arterial Hypertension Changes Literature Search and Inclusion Criterion}

We conducted a comprehensive search for studies of patients with $\mathrm{PAH}-\mathrm{CHD}$ who underwent correction. The literature was searched using MEDLINE, CNKI, WAN FANG, and Cochrane Library (up to December 2020). The screening methods of the three times are presented in Table 1.

\section{Interventional Closure and Surgery}

We counted 235 cases of $\mathrm{PAH}$ recurrence between interventional closure and surgery. To further understand this difference, we performed the literature search by criterion 1 . Firstly, the mean, sd, and $n$ values of PAH in the study were formally adjusted and compared between preoperative, postoperative, and follow-up groups ( $\mathrm{Li}$ and Li, 2020). Secondly, we performed a conventional meta-analysis to compare the therapeutic and prognostic outcomes of different operations. Differences were assessed by odds ratio (OR) with 95\% confidence intervals (CIs). The possibility of publication bias was estimated using funnel plots. Heterogeneity among studies was evaluated by calculating $p$-value and the $I^{2}$ measure of inconsistency, which was considered significant if $p<0.10$ and $I^{2}>50 \%$. All calculations were carried out using Review Manager 5.3 (The Nordic Cochrane Center, Copenhagen, Denmark).

\section{Drug Factors}

We reviewed the instructions for use of sildenafil and bosentan to ensure correct dosing. The literature was screened according to the criterion 2. At the same time, the dose of the two drugs was calculated according to the patient's body surface area. The 
TABLE 3 | PAH in nine studies including preoperative group, postoperative group, and follow-up group.

\begin{tabular}{|c|c|c|c|c|c|c|c|c|c|c|}
\hline \multirow[t]{2}{*}{ Study } & \multirow[t]{2}{*}{ Treatment } & \multicolumn{3}{|c|}{ Pre-operation PAH } & \multicolumn{3}{|c|}{ Post-operation PAH } & \multicolumn{3}{|c|}{ Follow-up PAH } \\
\hline & & Mean & SD & $\mathbf{N}$ & Mean & SD & $\mathbf{N}$ & Mean & SD & $\mathbf{N}$ \\
\hline Cao2017 & Interventional closure & 62.60 & 9.90 & 23 & 46.00 & 7.20 & 23 & 35.20 & 4.60 & 23 \\
\hline Cao2016 & Interventional closure & 46.90 & 8.49 & 25 & 35.66 & 10.53 & 25 & NA & NA & NA \\
\hline Jing2013 & Interventional closure & 59.24 & 15.00 & 62 & NA & NA & NA & 25.77 & 6.50 & 62 \\
\hline Sun2016 & Interventional closure & 30.30 & 6.30 & 28 & 27.30 & 5.60 & 28 & 24.80 & 2.10 & 28 \\
\hline Wang2020 & Interventional closure & 95.18 & 24.14 & 34 & 53.41 & 16.37 & 34 & 40.33 & 12.64 & 34 \\
\hline Zhang2012 & Interventional closure & 76.00 & 51.00 & 43 & 46.26 & 17.26 & 43 & NA & NA & NA \\
\hline Zhang2018 & Interventional closure & 58.00 & 24.00 & 64 & 36.00 & 11.00 & 64 & NA & NA & NA \\
\hline Zhao2013 & Surgical operation & 69.40 & 24.50 & 60 & 32.60 & 8.20 & 60 & NA & NA & NA \\
\hline Jing 2016a & Surgical operation & 65.30 & 9.50 & 6 & 24.00 & 1.40 & 6 & 32.10 & 3.50 & 6 \\
\hline Jing 2016b & Surgical operation & 72.20 & 11.40 & 14 & 33.20 & 4.20 & 14 & 43.80 & 4.30 & 14 \\
\hline Jing 2016c & Surgical operation & 83.50 & 13.60 & 12 & 44.80 & 4.50 & 12 & 53.50 & 5.40 & 12 \\
\hline Case review (closure) & Interventional closure & 79.94 & 30.24 & 52 & 60.63 & 32.43 & 52 & 54.12 & 26.98 & 52 \\
\hline Case review (operation) & Surgical operation & 70.77 & 22.64 & 172 & 39.76 & 18.04 & 172 & 44.25 & 22.37 & 172 \\
\hline
\end{tabular}

NA means there is no relevant value in the references.

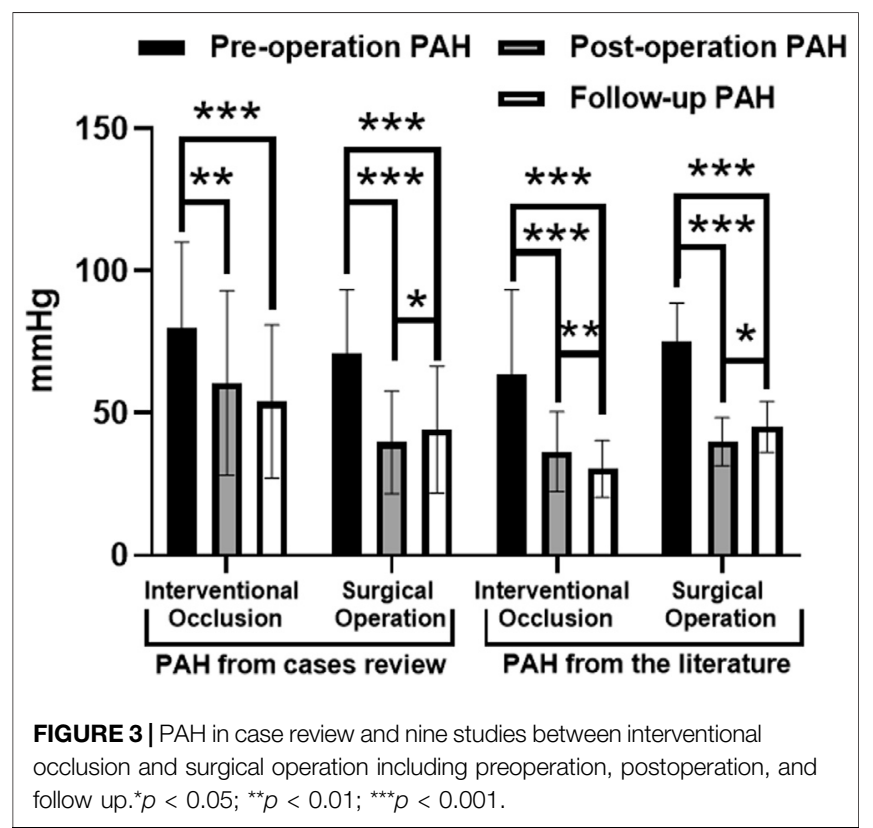

therapeutic and prognostic effects of three doses of sildenafil and bosentan were compared, including body surface dose (DBSA), literature dose (DL), and case review (DCR). Literature was screened according to the criterion 3 to compare the postoperative oral efficacy of the two drugs.

\section{Age Factors}

We divided 235 patients into five groups, namely infants ( $<1$ year), toddlers (1-6 years), children (7-14 years), adolescents (15-17 years), and adults ( $\geq 18$ years). Recurrence, preoperative $\mathrm{PAH}$, and treatment outcomes were analyzed for each group.

\section{Data Analysis}

Statistical analysis was performed using $t$-test and ANOVA. The $t$-tests and graphs of each drug safety indicators were applied in GraphPad Prism 8 (GraphPad Software, San Diego, Canada).
Results were considered statistically significant when the $p$-value was $<0.05$.

\section{RESULT}

\section{Patients' Characteristics}

Among 235 patients, the number of juvenile patients was approximately two times that of adult patients, but the proportion of $\mathrm{PAH}$ recurrences in the juvenile group was half that of adult group (37.02\%) (Table 2).

\section{Orthogonal Projections to Latent Structures Discriminant Analysis and S-Plot}

Using OPLS-DA with S-plot, we found four indicators: PAH, red blood cell (RBC), hemoglobin (HGB), and carbon dioxide levels in the blood $\left(\mathrm{CO}_{2}\right)$ (Figure 1). By analyzing the data of 4 indicators, it was found that $t$-test result is consistent with the result of the S-plot results.

We performed a statistical analysis of $\mathrm{PAH}$, including preoperative, postoperative, and follow-up periods (Figure 2). After treatment (interventional closure or surgery), $\mathrm{PAH}$ improved significantly, with a mean decrease of $28.85 \mathrm{mmHg}$. However, it increased in the postoperative follow-up group $60-90$ days $(p<0.05)$. There were no subnormal values of pulmonary artery systolic pressure $(36 \mathrm{mmHg})$ in the preoperative, postoperative, and follow-up groups, so we used PAH to represent pulmonary artery systolic pressure.

\section{Cause Analysis of Pulmonary Arterial Hypertension Changes Interventional Closure and Surgery}

Echocardiography of pre-treatment PAH was performed in 10 patients only and was not included in the analysis of $\mathrm{PAH}$ results. From a review of 224 cases, the recurrence rate of PAH of surgery $(50.83 \%, n=172)$ was higher than that of interventional closure $(41.26 \%, n=52)$. We selected nine 


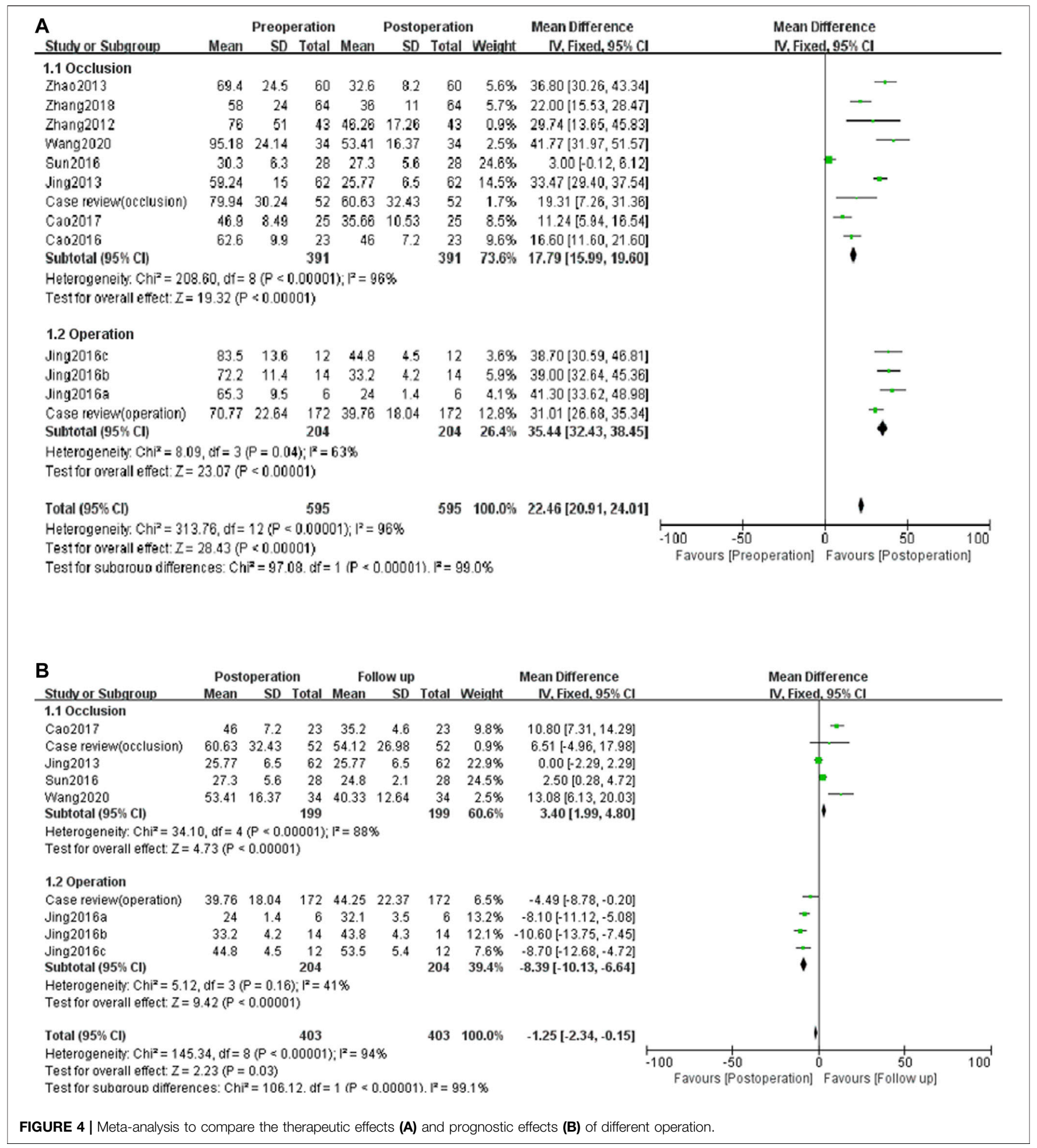

Chinese literature about patients with PAH-CHD who underwent correction according to criterion 1 (Table 3) (Zhang et al., 2012; Jing, 2013; Zhao, 2013; Cao et al., 2016; Jing et al., 2016; Sun et al., 2016; Zhang et al., 2016; Chao and Zhao, 2017; Wang et al., 2020). In Table 3, we also recorded the $\mathrm{PAH}$ of both groups in this case review.
As shown in Figure 3, similar trends in $\mathrm{PAH}$ in the case review and literature: 1) $\mathrm{PAH}$ decreases significantly after treatment, which was statistically significance $(p<0.05)$. The decrease in $\mathrm{PAH}$ after surgery was more significant than in the interventional closure group. 2) $\mathrm{PAH}$ decreased during follow-up in the interventional closure group, but was not statistically 
TABLE 4 | Body surface area dosage and dosage in literature of bosentan and sildenafil.

\begin{tabular}{|c|c|c|c|c|c|c|c|c|c|c|c|}
\hline & Weight, kg & Study & $<5$ & $\sim 20$ & $\sim 30$ & $\sim 35$ & $\sim 40$ & $\sim 45$ & $\sim 50$ & $\sim 60$ & $\sim 70$ \\
\hline & $\begin{array}{l}\text { Body surface } \\
\text { area, } \mathrm{m}^{2}\end{array}$ & Li2010 & \multicolumn{3}{|c|}{$0.035 \times$ Weight +0.1} & 1.2 & 1.3 & 1.4 & 1.5 & 1.6 & 1.7 \\
\hline Bosentan & $\begin{array}{l}\text { Body surface area } \\
\text { dosage, mg/day }\end{array}$ & & \multicolumn{3}{|c|}{$(0.035 \times$ Weight +0.1$) \times 147$} & 176 & 191 & 206 & 221 & 235 & 250 \\
\hline Sildenafil & $\begin{array}{l}\text { Body surface area } \\
\text { dosage, mg/day }\end{array}$ & & \multicolumn{3}{|c|}{$(0.035 \times$ Weight +0.1$) \times 35$} & 42 & 46 & 49 & 53 & 56 & 60 \\
\hline \multirow[t]{4}{*}{ Bosentan } & \multirow{4}{*}{$\begin{array}{l}\text { Dosage in literature, } \\
\text { mg/day }\end{array}$} & Mohamed2011 & 2 & NA & NA & NA & NA & NA & NA & NA & NA \\
\hline & & Steinhorn2016 & 4 & NA & NA & NA & NA & NA & NA & NA & NA \\
\hline & & Instruction & NA & 63 & 125 & 125 & 250 & 250 & 250 & 250 & 250 \\
\hline & & MAX & 4 & 62.5 & 125 & 125 & 250 & 250 & 250 & 250 & 250 \\
\hline \multirow[t]{6}{*}{ Sildenafil } & \multirow{6}{*}{$\begin{array}{l}\text { Dosage in literature, } \\
\text { mg/day }\end{array}$} & Al Omar2016 & 8 & NA & NA & NA & NA & NA & NA & NA & NA \\
\hline & & uslu2010 & 2 & NA & NA & NA & NA & NA & NA & NA & NA \\
\hline & & baquero2006 & 4 & NA & NA & NA & NA & NA & NA & NA & NA \\
\hline & & Robyn2011 & NA & 10 & 20 & 20 & 20 & 40 & 40 & 40 & 40 \\
\hline & & Carmine2017 & NA & NA & NA & NA & NA & NA & 60 & 60 & 60 \\
\hline & & MAX & 8 & 10 & 20 & 40 & 60 & 60 & 60 & 60 & 60 \\
\hline
\end{tabular}

NA means there is no relevant value in the references.
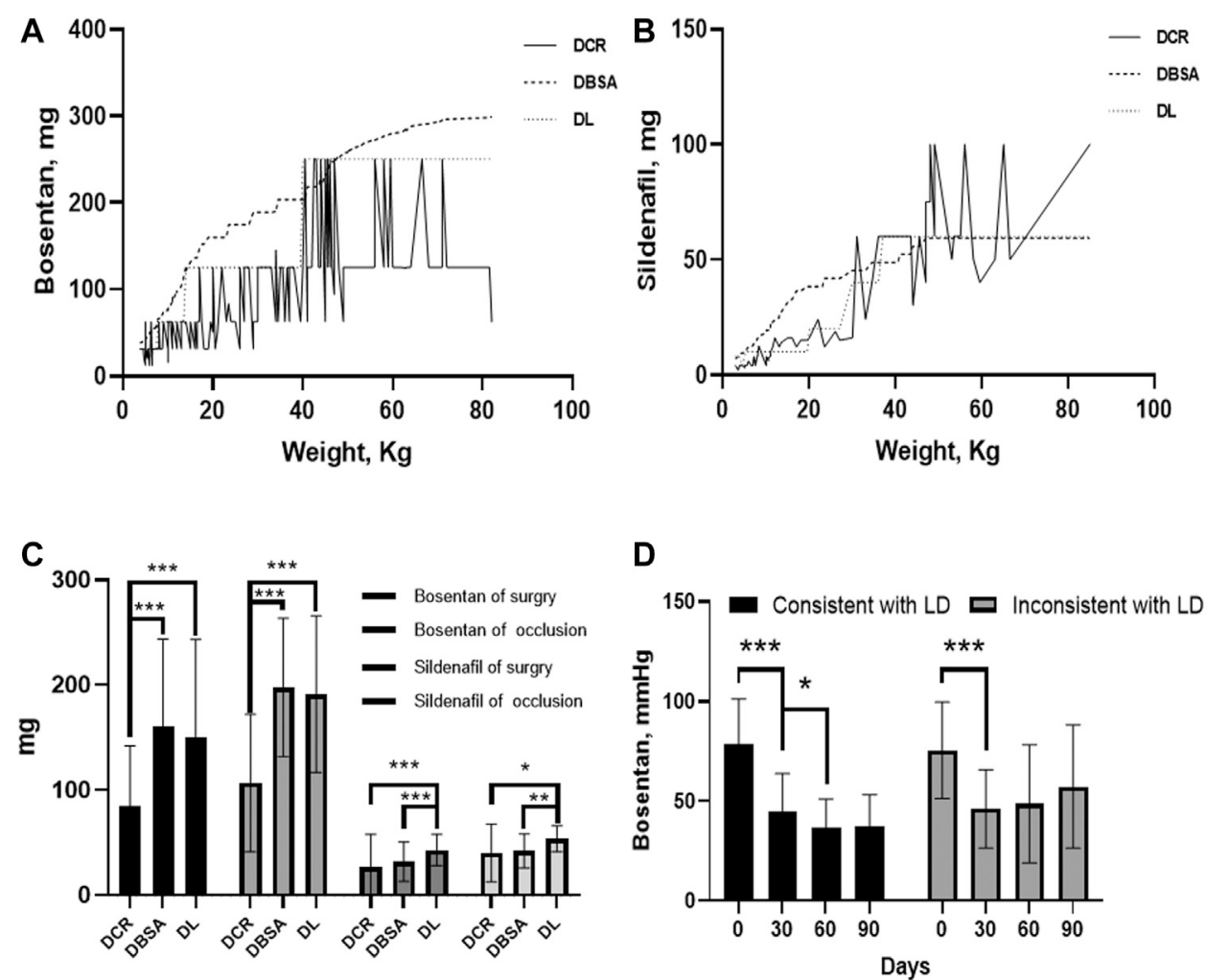

FIGURE 5 | The comparision of the therapeutic and prognostic effects of drug factors. Three doses were including dose based on body surface area (DBSA), dose based on literature (DL), and based on case review (DCR). (A) Curves of 3 doses of bosentan with body weight. (B) Curves of 3 doses of sildenafil with body weight. (C) Dose comparison of 3 doses of bosentan and sildenafil administered in different operations. (D) The variation of pulmonary artery pressure concerning the consistency or inconsistency of bosentan literature dosage. ${ }^{\star} p<0.05 ;{ }^{\star \star} p<0.01 ;{ }^{* \star *} p<0.001$.

significant in the case review, whereas it was statistically significant in the literature $(p<0.05)$. 3) $\mathrm{PAH}$ increased during follow-up in all surgical groups $(p<0.05)$. According to the meta-analysis (Figure 4), closure and surgery are feasible to reduce $\mathrm{PAH}$ in patients with $\mathrm{PAH}-\mathrm{CHD}\left(p<0.10, I^{2}>50 \%\right)$. Pulmonary artery pressure control was poor in the postoperative group $\left(I^{2}<50 \%\right)$, whereas it was good in the closed group $(p<$ $\left.0.10, I^{2}>50 \%\right)$.

\section{Drug Factors}

In order to study the appropriate dose, we selected seven literature through criterion 2 (Table 4) (Mohamed and Ismail, 2012; 
TABLE 5 | Comparison of recurrence and therapeutic effect in 5 age groups (Infant, toddlers, children, adolescent, and adult).

\begin{tabular}{|c|c|c|c|c|c|c|}
\hline & \multirow[t]{2}{*}{ Age } & \multirow[t]{2}{*}{ Recurrence, \% } & \multicolumn{3}{|c|}{ Preoperative $\mathrm{PAH}, \mathrm{mmHg}$} & \multirow[t]{2}{*}{ Therapeutic effect, $\mathrm{mmHg}$} \\
\hline & & & Mean & SD & $\mathbf{N}$ & \\
\hline Infant & $<1$ & 0.15 & 67.33 & 17.71 & 48 & 36.14 \\
\hline Toddlers & $1-6$ & 0.28 & 68.46 & 21.80 & 46 & 28.75 \\
\hline Children & $7-14$ & 0.38 & 71.27 & 26.94 & 47 & 31.69 \\
\hline Adolescent & $15-17$ & 0.50 & 82.16 & 30.49 & 22 & 32.47 \\
\hline Adult & $\geq 18$ & 0.53 & 77.91 & 26.91 & 72 & 30.86 \\
\hline
\end{tabular}

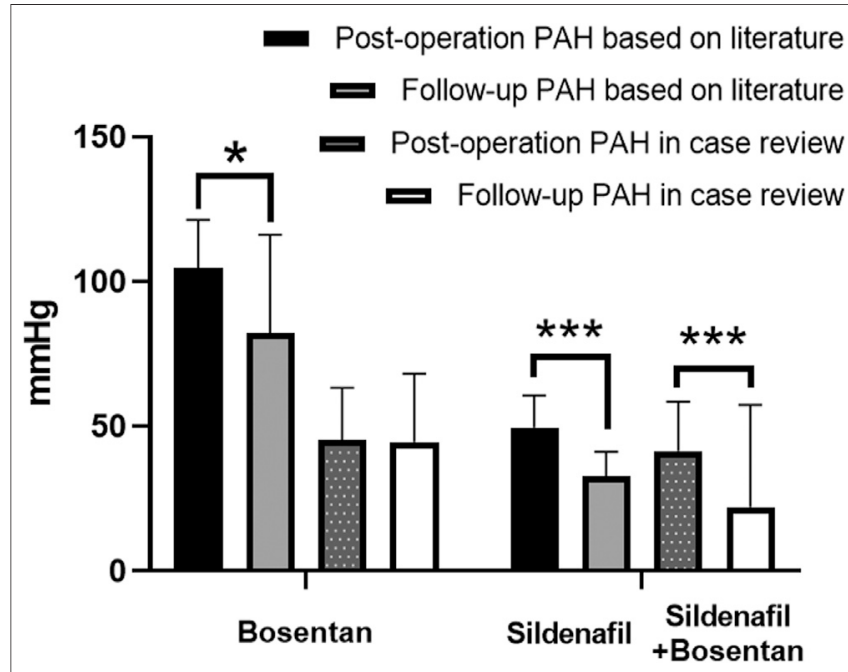

FIGURE 6 | Comparison of postoperative pulmonary pressure reduction effects between bosentan and sildenafil in case review and literature. ${ }^{*} p<$ $0.05 ;{ }^{* \star} p<0.01 ;{ }^{\star \star \star} p<0.001$.

Steinhorn et al., 2016; Omar et al., 2016; Hernando and Amed, 2006; Sinan et al., 2011; Robyn et al., 2011; Carmine et al., 2017). According to the literature, we listed the corresponding body surface area with different body weights and the calculated dose of two drugs based on the body surface area (Li, 2010). As shown in Figure 5, the actual doses of bosentan and sildenafil were insufficient when compared with the dosage in the literature and surface area calculated. The dosage in consistent with the literature and the dosage in inconsistent with the literature were divided into two groups. It was found that the literature group still had a statistically significant reduction in PAH after 30 to 60 days of follow-up $(p<0.05)$. On the other hand, the group that did not follow the literature dosage showed a sustained increase in $\mathrm{PAH}$ after 30 days of follow-up.

In order to study the postoperative treatment effect of these two drugs, two literature were screened out by criterion 3 . Since no literature was found on postoperative combination therapy (sildenafil and bosentan), this study focused only on the effect of postoperative sildenafil monotherapy (Cheng et al., 2014; Yang, 2014). We found a statistically significant reduction in PAH in both the literature group of sildenafil and the case review group with combination therapy $(p<0.05)$. Bosentan reduced PAH only in the literature group, which was statistical difference in Figure 6 $(p<0.05)$.

\section{Age Factors}

We divided 235 patients into five groups (48 infants, 46 toddlers, 47 children, 22 adolescents, and 72 adults) (Table 5). The number of minors hospitalized for PAH-CHD was twice as many as adults (163:72). The best treatment outcome $(36.14 \mathrm{mmHg})$ and the lowest recurrence rate $(0.15 \%)$ were observed mainly in infants.

\section{DISCUSSION}

\section{Orthogonal Projections to Latent Structures-Discriminant Analysis and S-Plot}

OPLS-DA could be applicable to the analysis from routine clinical examination data, and S-plot could be helpful to screen out the indicators. We believe that simple methods such as OPLS-DA and S-plot are extremely important for screening prognostic indicators, in terms of saving doctors' time to read the checklist and saving patients' medical examination costs than PCA. Although four indicators $\left(\mathrm{PAH}, \mathrm{RBC}, \mathrm{HGB}\right.$, and $\left.\mathrm{CO}_{2}\right)$ were screened out in this paper, few studies have used $\mathrm{RBC}, \mathrm{HGB}$, and $\mathrm{CO}_{2}$ as prognostic indicators.

\section{Cause Analysis of Elevated Pulmonary Arterial Hypertension Reasons for the Operation}

Combined with the literature and the case review in this study, surgery is inferior to closure. This phenomenon is widespread. The reason for this phenomenon might due to surgery requiring open chest and extracorporeal blood circulation. In contrast, the closure is less invasive and reduces the risk of infection. In this study, although the inclusion criterion for three times literature retrievals were consulted English and Chinese, almost most of the included literature was in Chinese (Suzuki et al., 2017; Akagi et al., 2018; Zwijnenburg et al., 2018). This might be because Chinese researchers might be more concerned with the follow-up of postoperative $\mathrm{PAH}$, while researchers in other countries might pay more attention to the outcome of the operation itself. To improve patient survival, we believe that the postoperative followup of patients with PAH-CHD (detection of adverse factors and timely intervention) is very important. We hope that more researchers studying $\mathrm{PAH}$ will focus on the long-term postoperative follow-up to optimize the treatment and even 
provide a basis for treatment recommendations for patients with PAH-CHD.

\section{Reasons for the Drug}

The effect of combination therapy (bosentan and sildenafil) was more effective than that of bosentan. This result is consistent with the results of meta-analysis ( $\mathrm{Li}$ et al., 2020). We propose that the main reason for poor postoperative control might be caused by insufficient dose and inappropriate medication. Most of the patients with $\mathrm{PAH}-\mathrm{CHD}$ in our hospital were pediatric patients. Unfortunately, The drug dosage of these patients was not indicated on the packaging of bosentan and sildenafil. The commonly used method to determine the dosage of pediatric medicine is to convert it according to body weight, body surface area, or adult dosage. One study argued that doses should be calculated according to the $2 / 3$ power of body weight (West, 2018). For example, Bosentan $60 \mathrm{~kg}$ adult dose is $250 \mathrm{mg} /$ day, then the daily dose for a $10 \mathrm{~kg}$ toddler is $250 /(60 / 10)^{2 / 3} \approx 75 \mathrm{mg}$. However, no matter which method is used to calculate, the dosage of drugs in some patients was far from adequate. We also consider the efficacy of controlling postoperative pulmonary arterial pressure by standardizing patient dosing, which requires further study.

\section{Reasons for the Age}

The younger the patient's age, the more effective the reduction in $\mathrm{PAH}$. As the patient ages, the CHD might lead to cardiac remodeling and pulmonary artery function. Also, Also, damage to multiple organs may occur in the body due to chronic hypoxia, and a sudden increase in oxygen saturation does not reverse the damage. Therefore, we strongly recommend early operation (closure or surgery) for patients with $\mathrm{CHD}$ to improve the recovery outcome.

\section{CONCLUSION}

For the first time, OPLS-DA combined with S-plot was used to analyze clinical examination data, and four indicators $\mathrm{PAH}$, $\mathrm{RBC}, \mathrm{HGB}$, and $\mathrm{CO}_{2}$ ) reflecting patients' prognosis were found. We suggest that occlision therapy would be preferred in patients with PAH-CHD. To prevent recurrence, the dose should be formally prescribed according to the instructions or literature

\section{REFERENCES}

Akagi, S., Kasahara, S., Sarashina, T., Nakamura, K., and Ito, H. (2018). Treat-andrepair Strategy is a Feasible Therapeutic Choice in Adult Patients with Severe Pulmonary Arterial Hypertension Associated with a Ventricular Septal Defect: Case Series. Eur. Heart J. Case Rep. 2 (2), yty033. doi:10.1093/ehjcr/yty033

Ashraf, A. H. E., and Midany, E. A. (2013). Etc. Perioperative Sildenafil Therapy for Pulmonary Hypertension in Infants Undergoing Congenital Cardiac Defect Closure[J]. Interact Cardiovasc. Thorac. Surg. 17 (6), 963-968. doi:10.1093/ icvts/ivt353

Cao, L. M., Jin, B., Wang, F. M., et al. (2016). Clinical Analysis of Unclosed Ductus Arteriosus in Children with Severe Pulmonary Hypertension [J]. J. Nanjing for use. The effect of combination therapy (bosentan and sildenafil) is more effective than that of bosentan. The younger the patient is, the more effective the treatment is.

\section{DATA AVAILABILITY STATEMENT}

The original contributions presented in the study are included in the article/Supplementary Material, further inquiries can be directed to the corresponding author.

\section{ETHICS STATEMENT}

The studies involving human participants were reviewed and approved by the Ethics Committee of Yunnan Fuwai Cardiovascular Disease Hospital. Written informed consent from the participants' legal guardian/next of kin was not required to participate in this study in accordance with the national legislation and the institutional requirements.

\section{AUTHOR CONTRIBUTIONS}

XL: Data analysis, discussion, the meta-analysis methods and results, data extraction and quality control was performed. TL: Quality control.

\section{FUNDING}

This research was funded by Yunnan Clinical Medical Center of Fuwai Yunnan Cardiovascular Hospital, Project No. 2020YFKT13, and Scientific Research Fund of Yunnan Provincial Education Department, Project No. 2021J0292.

\section{ACKNOWLEDGMENTS}

We wish to thank the colleagues from Fuwai Yunnan Cardiovascular Hospital for their support. We also wish to thank the professors and schoolmates from Kunming Medical University.

Med. Univ. (Natural Science). 36 (12), 1534-1537. doi:10.7655/ NYDXBNS20161236

Carmine, D., Sastry, B., and Zeenat, S. (2017). etc.Efficacy of 1, 5, and $20 \mathrm{Mg}$ Oral Sildenafil in the Treatment of Adults with Pulmonary Arterial Hypertension: a Randomized, Double-Blind Study with Open-Label Extension[J]. BMC Pulm. Med. 17, 44-56. doi:10.1186/s12890-017-0374-x

Chao, J., and Zhao, L. L. (2017). Changes in Pulmonary Artery Pressure after Atrial Septal Defect Closure in Adults [J]. Chin. J. Contemp. Med. 24 (028), 36-38. doi:10.3969/j.issn.1674-4721.2017.28.012

Cheng, G. H., Zhang, Y. S., and Du, Y. J. (2014). etc.Targeted-drug Combined with Interventional Therapy in the Treatment of Congenital Heart Disease Complicated with Severe Pulmonary Hypertension [J]. J. Cardiovasc. Surg. 3 (01), 19-22. CNKI: XXGW. 0.2014-01-005 
Gilbert, N., Luther, Y.-C., Miera, O., Nagdyman, N., Ewert, P., Berger, F., et al. (2005). Initial Experience with Bosentan (Tracleer) as Treatment for Pulmonary Arterial Hypertension (PAH) Due to Congenital Heart Disease in Infants and Young Children. ZS Kardiologie. 94 (9), 570-574. doi:10.1007/ s00392-005-0266-6

Hernando, B., and Amed, etc. (2006). Oral Sildenafil in Infants with Persistent Pulmonary Hypertension of the Newborn: a Pilot Randomized Blinded study.[J]. Pediatrics. 117 (4), 1077-1083. doi:10.1542/peds.2005-0523

Jing, W. R. (2013). Interventional Therapy for Patients with Atrial Septal Defect and Moderate to Severe Pulmonary Hypertension: A Follow-Up Study [D]. Kunming: Kunming Medical University

Jing, X. Y., Yang, X. Y., Su, J. W., et al. (2016). Clinical Study on Diagnostic Treatment of Congenital Heart Disease Complicated with Severe Pulmonary Hypertension [J]. J. Cardiopulmonary Vasc. Dis. 35 (04), 293-296. doi:10.3969/ j.issn.1007-5062.2016.04.011

Kelly, L. E., Ohlsson, A., and Shah, P. S. (2017). Sildenafil for Pulmonary Hypertension in Neonates. Cochrane Database Syst. Rev. 8 (8), CD005494. doi:10.1002/14651858.CD005494.pub4

Kiefer, T. L., and Bashore, T. M. (2011). Pulmonary Hypertension Related to LeftSided Cardiac Pathology[J]. Pulm. Med. 2011 (2090-1836), 381787. doi:10. $1155 / 2011 / 381787$

Li, H. Z., Gong, Y. Y., and Xu, W. X. (2020). Meta-analysis of Bosentan Combined with Sildenafil in the Treatment of Pulmonary Hypertension [J]. J. Clin. Ther. 18 (01), 63-68. doi:10.3969/j.issn.1672-3384.2020.01.015

Li, X., and Li, T. (2020). Combined Methods (Formal Adjusted Indirect Comparison, Meta-Analysis and Principal Component Analysis) Comparisons of the Safety and Efficacy of Ambrisentan, Bosentan, and Sildenafil in the Patients with Pulmonary Arterial Hypertension. Front. Pharmacol. 11, 400. doi:10.3389/fphar.2020.00400

Li, Z. F. (2010). Practical Pediatric Drug Dose Survey Manual [M]. Beijing: China Medical Science and Technology Press, 4-5.

Mclaughlin, V. V., Archer, S. L., Badesch, D. B., Barst, R. J., Farber, H. W., Lindner, J. R., et al. (2009). ACCF/AHA 2009 Expert Consensus Document on Pulmonary Hypertension. J. Am. Coll. Cardiol. 53 (17), 1573-1619. doi:10.1016/j.jacc.2009. 01.004

Melby, S. J., Moon, M. R., Lindman, B. R., Bailey, M. S., Hill, L. L., and Damiano, R. J. (2011). Impact of Pulmonary Hypertension on Outcomes after Aortic Valve Replacement for Aortic Valve Stenosis. J. Thorac. Cardiovasc. Surg. 141 (6), 1424-1430. doi:10.1016/j.jtcvs.2011.02.028

Mohamed, W. A., and Ismail, M. (2012). A Randomized, Double-Blind, PlaceboControlled, Prospective Study of Bosentan for the Treatment of Persistent Pulmonary Hypertension of the Newborn. J. Perinatol. 32 (8), 608-613. doi:10. 1038/jp.2011.157

More, K., Athalye-Jape, G. K., Rao, S. C., and Patole, S. K. (2016). Endothelin Receptor Antagonists for Persistent Pulmonary Hypertension in Term and Late Preterm Infants. Cochrane Database Syst. Rev. (8), CD010531. doi:10.1002/ 14651858.CD010531.pub2

Nazzareno, G., Humber, M., and Ronald, J. (2016). Etc. 2015 ESC/ERS Guidelines Fro the Diagnosis and Treatment of Pulmonary Hypertension[J]. Eur. Heart J. 37, 69-119. doi:10.1183/13993003.01032-2015

Omar, S. A., Salama, H., and Hail, M. A. (2016). Etc. Effect of Early Adjunctive Use of Oral Sildenafil and Inhaled Nitric Oxide on the Outcome of Pulmonary Hypertension in Newborn Infants. A Feasibility Study[J]. J. Neonatal-Perinatal Med. 9 (3) ,251-259. doi:10.3233/NPM-16161

Robyn, J., Dunbar, I., and Guillermo, G. (2011). etc.A Randomized, DoubleBlind, Placebo-Controlled, Dose-Ranging Study of Oral Sildenafil Citrate in Treatment-Naive Children with Pulmonary Arterial Hypertension[J]. Pediatr. Cardiol. 7, 324-334. doi:10.1161/CIRCULATIONAHA.110. 016667
Sinan, U., Soner, K., and Ali, B. (2011). Etc. A Comparison of Magnesium Sulphate and Sildenafil in the Treatment of the Newborns with Persistent Pulmonary Hypertension: A Randomized Controlled Trial[J]. J. Trop. Pediatr. 57 (4), 245. doi:10.1093/tropej/fmq091

Steinhorn, R. H., Fineman, J., Kusic-Pajic, A., Cornelisse, P., Gehin, M., Nowbakht, P., et al. (2016). Bosentan as Adjunctive Therapy for Persistent Pulmonary Hypertension of the Newborn: Results of the Randomized Multicenter PlaceboControlled Exploratory Trial. J. Pediatr. 177, 90-96.e3. doi:10.1016/j.jpeds. 2016.06.078

Sun, W. F., Zhu, M. X., and Cui, T. (2016). A Follow-Up Study of Left Heart Function after Patent Ductus Arteriosus Closure by Transthoracic Echocardiography [J]. Chin. J. Interv. Cardiol. 24 (02), 74-78. doi:10.3969/j.issn.1004-8812.2016.02.003

Suzuki, H., Hanawa, H., Torigoe, T., and Sato, S. (2017). Improvement of Pulmonary Arterial Hypertension Following Medication and Shunt Closure in a BMPR2 Mutation Carrier with Atrial Septal Defect. J. Cardiol. Cases. 16 (1), 11-13. doi:10.1016/j.jccase.2017.03.005

Wang, Z. Y., Jin, M., and Wang, X. F. (2020). Interventional Treatment and FollowUp Study of Adults with Unclosed Ductus Arteriosus and Severe Pulmonary Hypertension [J]. J. Cardiopulmonary Vasc. Dis. 39 (01), 27-35. doi:10.3969/j. issn.1007-5062.2020.01.005

West, G. (2018). Scale: The Universal Laws of Growth, Innovation, Sustainability, and the Pace of Life in Organisms,cities, Economies, and companies[M]. New York: Penguin Books

Xi, S.-B., Wang, S.-S., Qian, M.-Y., Xie, Y.-M., Li, J.-J., and Zhang, Z.-W. (2019). Predictors of Operability in Children with Severe Pulmonary Hypertension Associated with Congenital Heart Disease. Chin. Med. J. 132 (7), 811-818. doi:10.1097/CM9.0000000000000145

Yang, S. Q. (2014). Clinical Observation of Sildenafil in Treatment of Pulmonary Hypertension after Surgery for Congenital Heart Disease [J]. J. Clin. Med. 34 (03), 43-45. CNKI:SUN:EBED.0.2014-03-029

Zhang, C. H., Wang, J. P., and Tian, Y. (2016). etc.Comparison of Pulmonary Arterial Pressure and Blood Pressure before and after Patent Ductus Arteriosus Interventional Closure [J]. Guizhou Med. Sci. 40 (01), 16-18. doi:10.3969/j.issn. 1000-744X.2016.01.006

Zhang, K. C., Yuan, J., and Yu, B. (2012). Etc. Study on Changes of Pulmonary Artery Pressure after Interventional Treatment of Patent Ductus Arteriosus [J] J. Cardiovasc. Rehabil. Med. 021 (004), 409-412. doi:10.3969/j.issn.1008-0074. 2012.04.23

Zhao, Q., Li, X.-M., Liu, H.-N., Gonzalez, F. J., and Li, F. (2017). Metabolic Map of Osthole and its Effect on Lipids, Xenobiotica. 48, 285-299. doi:10.1080/ 00498254.2017 .1306660

Zhao, X. B. (2013). Follow-up Study after Unclosed Ductus Arteriosus and Pulmonary Hypertension Closure [D]. Shandong: Shandong University. doi:10.7666/d.y2433747

Zwijnenburg, R. D., Baggen, V. J. M., Geenen, L. W., Voigt, K. R., Roos-Hesselink, J. W., and van den Bosch, A. E. (2018). The Prevalence of Pulmonary Arterial Hypertension before and after Atrial Septal Defect Closure at Adult Age: A Systematic Review. Am. Heart J. 201, 63-71. doi:10.1016/j.ahj.2018.03.020

Conflict of Interest: The authors declare that the research was conducted in the absence of any commercial or financial relationships that could be construed as a potential conflict of interest.

Copyright (c) $2021 \mathrm{Li}$ and Li. This is an open-access article distributed under the terms of the Creative Commons Attribution License (CC BY). The use, distribution or reproduction in other forums is permitted, provided the original author(s) and the copyright owner(s) are credited and that the original publication in this journal is cited, in accordance with accepted academic practice. No use, distribution or reproduction is permitted which does not comply with these terms. 